Research Article

\title{
Analysis of drug prescribing trends in treatment of rheumatoid arthritis at a tertiary care hospital, Karnataka, India
}

\author{
Dharani Devangi Ranganath ${ }^{1}$, Deeptangshu Ganguly ${ }^{2}$, Manjunatha Shankarappa ${ }^{3}$, \\ Kokila Bengaluru Nagaraj ${ }^{4}$, Rajasekhar Chintha ${ }^{5}$
}

${ }^{1}$ Department of Pharmacology, Shimoga Institute of Medical Sciences, India

${ }^{2}$ Department of Pharmacology, IQ city Medical College, Durgapur, West Bengal, India ${ }^{3}$ Department of Orthopedics, ${ }^{4}$ Department of Pharmacology, KVG Medical College and Hospital, Sullia, Karnataka, India

${ }^{5}$ Department of Pharmacology, MM Medical College, Manipal, India

Received: 02 September 2016 Accepted: 12 September 2016

\section{*Correspondence to:}

Dr. Dharani Devangi Ranganath, Email: dharanidevangi2707 @ gmail.com

Copyright: () the author(s), publisher and licensee Medip Academy. This is an openaccess article distributed under the terms of the Creative Commons Attribution NonCommercial License, which permits unrestricted noncommercial use, distribution, and reproduction in any medium, provided the original work is properly cited.

\begin{abstract}
Background: This study proposes compilation, analysis of pattern, trend, rationality and frequency of use of drugs in the treatment of rheumatoid arthritis with emphasis on available treatment regimens inclusive of primary and adjunctive therapy.

Methods: The study records relevant data obtained from medical case records of patients suffering from RA above 15 years age excluding pregnancy and other arthritis, attending orthopedic OPD at KVGMC, Sullia (D.K), Karnataka, prospectively for a period of 15-18 months starting from December 2013 to June 2015.

Results: 217 patients suffering from RA were analyzed and recorded. RA was more common among the age group of 45 to 50 with female predominance $(64 \%)$. RF positivity was seen in $42 \%$ cases. Out of 11 classes of drugs prescribed DMARDs (249), corticosteroids (225) and analgesics (217) played major role in treatment outcome. Non-biological DMARDs (94\%) were more commonly prescribed, of which methotrexate (120) \& hydroxychloroquine (128) were frequently administered. Very few patients received biological DMARDs like etanercept and infliximab. Both oral and IV preparations of corticosteroids were administered. Among the adjuvant group of drugs NSAIDs (130), opioids (53), Muscle relaxants (33), pregabalin (26), sedative/hypnotics (102) nutritional supplements (214), anti-gastric (201), antiemetic's (13), antihistamines (4) were prescribed accordingly. Treatment outcome was assessed at the end of 15 months and 163 patients were relieved from symptoms but no remission but there was significant association between treatment outcome and duration of treatment with DMARDs.

Conclusions: The treatment outcome and the duration of illness have significantly improved with rational use of DMARDs. Thus the study highlights and creates awareness on rational use of therapeutic agents available for treatment of RA and provides feedback to the prescriber.
\end{abstract}

Keywords: Rheumatoid arthritis, DMARDs, NSAIDs, Rational drug use

\section{INTRODUCTION}

Prescription writing is an art as it reflects the instructions given by the prescriber to the patient. ${ }^{1}$ Prescribing practice reflects health professional's abilities to discriminate among the various choices of drugs and determine the ones that will benefit their patients most. ${ }^{2,3}$
Irrational prescription of drugs is not an uncommon occurrence in clinical practice. The cost of such irrational drug-use is enormous in terms of both scarce resources and the adverse clinical consequences of therapies that may have real risks but no objective benefits. This is especially true in case of developing countries such as India with a huge population that makes access to health care delivery systems difficult. Improper prescribing 
habits lead to ineffective and unsafe treatment, exacerbation or prolongation of illness, distress and harm to the patient and higher costs. ${ }^{1,4}$ The rational use of drugs stresses on "patients receiving medications appropriate to their clinical needs, in doses that meet their own individual requirements for an adequate period of time, at the lowest cost to them and their community". The study of prescription pattern is an important component of medical audit which helps in monitoring, evaluating and making necessary modifications in the prescribing practices to achieve a rational and cost effective medical care. Auditing of prescriptions forms an important part of drug utilization studies. ${ }^{6}$

Rheumatoid arthritis is a systemic autoimmune disease, characterized by chronic joint inflammation leading to destruction of bone and cartilage resulting in decrease of functional capacity and increased morbidity. As it is a systemic disease, it may result in a variety of extraarticular manifestations, including fatigue, subcutaneous nodules, lung involvement, pericarditis, peripheral neuropathy, vasculitis, and hematologic abnormalities. ${ }^{7,8}$

Community studies point to a prevalence of $0.5 \%$ to $1 \%$ in adult population worldwide. About $0.75 \%$ of adult Indian population is affected by the disease. The incidence of RA increases between 25 and 55 years of age, after which it plateaus until the age of 75 and then decreases. Prevalence is estimated to be $0.2-0.4 \%$ in Asia, with women twice as likely to develop the disease as men, with a ratio of $2-3: 1 .^{8-10}$

The prevalence of chronic diseases in modern industrialized nations is increasing and among these intractable conditions RA stands out as a major cause of multiple medical problems. An estimated 1-3\% of the population is affected by the disease, while about two thirds of cases suffer significant social and economic disadvantages. The affected individuals experience significant morbidity including loss of function, joint destruction and permanent deformity with higher mortality than in general population. Hence long term efficacy and tolerability of available therapies should be assessed. $^{11}$

Several treatment strategies have proven value in the amelioration of RA, but the optimal strategy for preventing long term joint damage and functional decline is unclear. ${ }^{12}$ The utilization of DMARDS has increased in TennCare (Tennessee Medicaid database) patients with RA and use of biologics has become substantial. Although glucocorticoid utilization has decreased, use of both NSAIDs and narcotics has increased. ${ }^{13}$

Pharmacotherapy of RA includes the following,

- Anti-inflammatory drugs: NSAIDs and corticosteroids

- Opioid analgesics
- Conventional disease modifying anti rheumatoid drugs (non-biological DMARDs)

- Biological DMARDs. $^{14}$

The majority of patients with a confirmed diagnosis of RA use non biological DMARDs and the rate of biologic DMARD use is raising rapidly. ${ }^{15}$

In this context, the availability of a wide variety of therapeutic agents such as NSAIDs (non-steroidal antiinflammatory drugs) and DMARDs (disease modifying anti rheumatoid drugs) is noteworthy, although the safety profile of these drugs is debatable.

Over the last two decades, the treatment of patients with rheumatoid arthritis has changed considerably. Currently the goal of therapy is not only symptom relief, but in particular, the prevention of long term structural damage and functional decline. ${ }^{16}$

Various studies have been found indicating the benefits of monotherapy, combination therapy and factors predicting the response in treatment of RA.

Periodic evaluation of drug utilization/prescription patterns needs to be done to enable suitable modifications in prescription of drugs to increase the therapeutic benefit and minimize the adverse effects. The study of prescription patterns seeks to monitor and evaluate the prescribing trend of medical practitioners. These studies aim to provide feedback to the prescriber and to create awareness among them about the rational use of medicines.

Accordingly, in view of the said observations, this study proposes compilation, analysis of pattern, trend, rationality and frequency of use of drugs in the treatment of rheumatoid arthritis with emphasis on available treatment regimens inclusive of primary and adjunctive therapy.

\section{Objectives}

- To analyze/evaluate the trend and pattern of drug prescriptions for rheumatoid arthritis in a teaching hospital

- To study the specific and adjunctive drug therapy

- To monitor adverse effects if any, subject to compliance of the patients.

\section{METHODS}

\section{Place of the study}

The study was undertaken in co-ordination with teaching and nonteaching staffs of the department of orthopaedics at KVG medical college and teaching hospital, Sullia, D.K. 


\section{Design and duration of the study}

A prospective, non-interventional, observational medical audit- study was undertaken during the period December 2013 to June 2015 including first one month of pilot study.

\section{The pilot study}

In order to gain familiarity with the topic and data collection, a pilot study was conducted over a period of one month.

Accordingly a special proforma was designed and data were obtained from medical case records of patients suffering from RA, attending the department of orthopaedic surgery, KVG Medical College Hospital, Sullia (D.K), Karnataka.

Subsequently, a few modifications were made in the said Performa as per requirements for the current study.

The primary objectives of conducting a pilot study were to confirm,

- The feasibility of carrying out this study.

- The availability of patients suffering from the RA at the KVGMCH, Sullia.

- The need if any, for modifying the Performa further to facilitate the collection of relevant data.

Over a period of 18 months, earnest attempts were made to record the details of as many available cases as possible both prospectively and retrospectively in regard to sample size and a total of 217 patients suffering from RA received treatment and this sample was considered to be adequate for the study noting the prevalence of RA in India. Institutional Ethical committee clearance was obtained for this study. Data collection was undertaken with following inclusion and exclusion criteria.

\section{Inclusion criteria}

Patients above the age of 15 years of either gender suffering from rheumatoid arthritis exclusively, reporting at KVG Medical College Hospital, Sullia.

\section{Exclusion criteria}

Patients below 15 years of age, Patients with other kinds of arthritis such as osteoarthritis, psoriatic arthritis, infective arthritis (septic arthritis) and Pregnancy.

\section{Data collection}

The investigator met and sought help of staff, Head of the Department of Orthopaedics with regard to the conduct of study. The investigator attended the out-patient department of orthopaedic daily and recorded data of patients attending orthopaedic OPD and also those who were admitted in wards with rheumatoid arthritis. The list of all patients suffering from RA was made. Drug therapy prescribed to those patients was recorded. With regards to in patients, in wards data was obtained from patient's case reports. Details were obtained regarding the duration of illness, severity, onset of illness, diagnostic criteria, radiological evidence, associated other systemic illness and adverse drug reactions if any either pertaining to present illness or an interaction of drugs taken for other systemic illness were recorded. Treatment outcome was analysed at the end of 15 months using ACR/EULAR criteria for remission. The relevant data was collected on a proforma by the investigator in person from the medical case records pertaining to the department of Orthopaedic at KVGMCH, Sullia.

The specially designed proforma consisted of information on the following:

- Demographic data: Name, age, address, OP/IP number, date of examination/admission of patients.

- Disease data: Onset and duration of rheumatoid arthritis.

- Data pertaining to drug therapy: Drug/drugs prescribed, dose, frequency, duration and route of administration.

- Data pertaining to investigations: Serum RA factor tests, radiographic findings if any.

- Data pertaining to other systemic illness the patient is suffering from, if any.

- Data pertaining to adverse effects of drugs, if any.

\section{Statistical analysis}

The data thus obtained were subjected to statistical analysis. Descriptive statistical analysis was done using Microsoft office excel 2013 and qualitative analysis of data was performed using Pearson's Chi-square test by SPSS software version 19.

\section{RESULTS}

This prospective study was conducted on patients suffering from rheumatoid arthritis above the age of 15 years. The study reports 217 case records which were critically analysed.

Table 1: The Mean age group of male and female patients with RA.

\begin{tabular}{|lll|}
\hline Gender & Mean age & Std error \\
\hline Male & 43.80 & 0.99 \\
\hline Female & 47.69 & 1.71 \\
\hline
\end{tabular}

Rheumatoid arthritis was more commonly reported in persons with mean age of $45.75 \pm 0.98$. The mean age group of male and female patients accordingly are represented in Table 1. RA was more common in females $64 \%$ than in males $36 \%$ (Figure 1). Of all RA cases 
recorded in this study RA factor positivity was seen with 92 patients $(42 \%)$ showing female predominance with 69 patients (75\%) (Figure 2a, 2b).

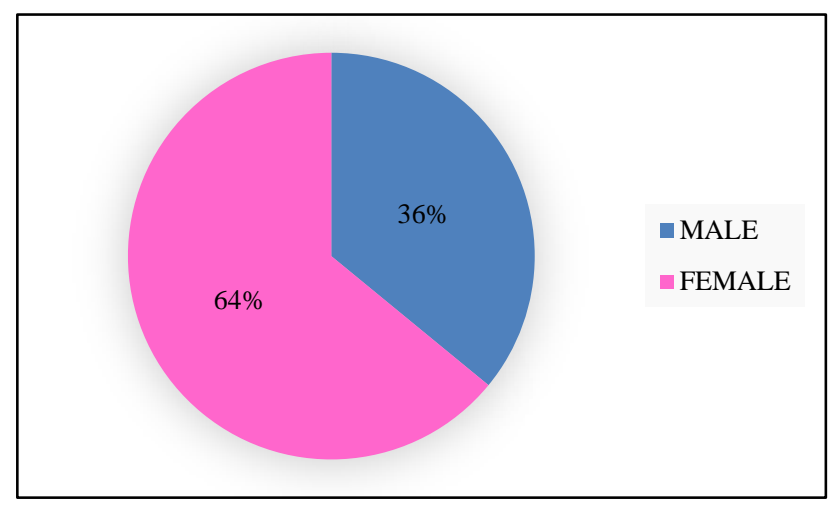

Figure 1: Gender prevalence.

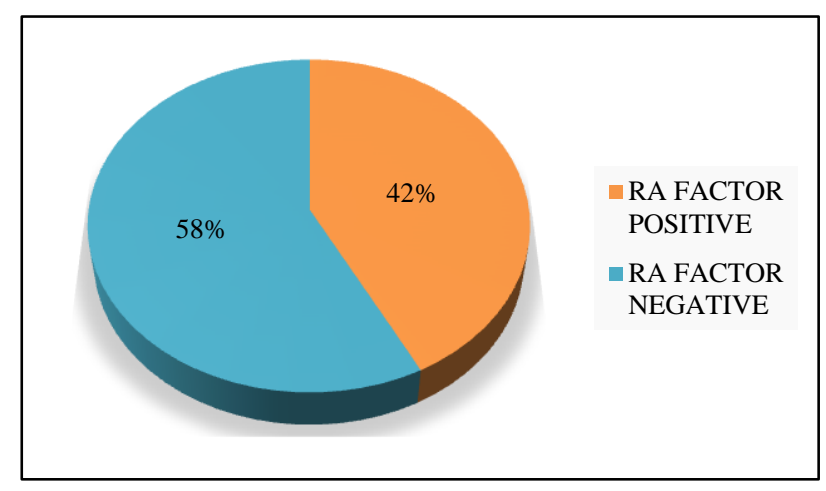

Figure 2a: Patients with RA positivity.

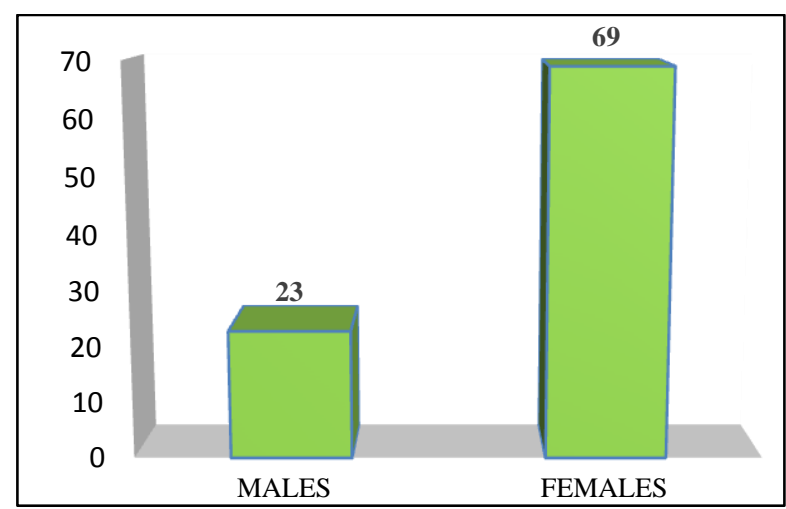

Figure 2b: Gender distribution among RA positive patients.

Figure 3 shows overall drug prescription pattern in RA consisting of numerous classes of drugs such as DMARDS, corticosteroids, NSAIDs, opioid analgesics, muscle relaxants, pregabalin, nutritional supplements, anti-gastric drugs, antiemetic's, anti-histamines and sedative hypnotics. Of which DMARDs, NSAIDs and opioid analgesics, corticosteroids, anti-gastric drugs and nutritional supplements play a very important role. DMARDs constituted the major group of drugs in treatment of RA, non-biological DMARDs were prescribed more commonly than biological DMARDs with mean usage of DMARDs being 1.57 \pm 0.06 and 1 respectively (Table 2, Figure $3 a, 3 b$ ).

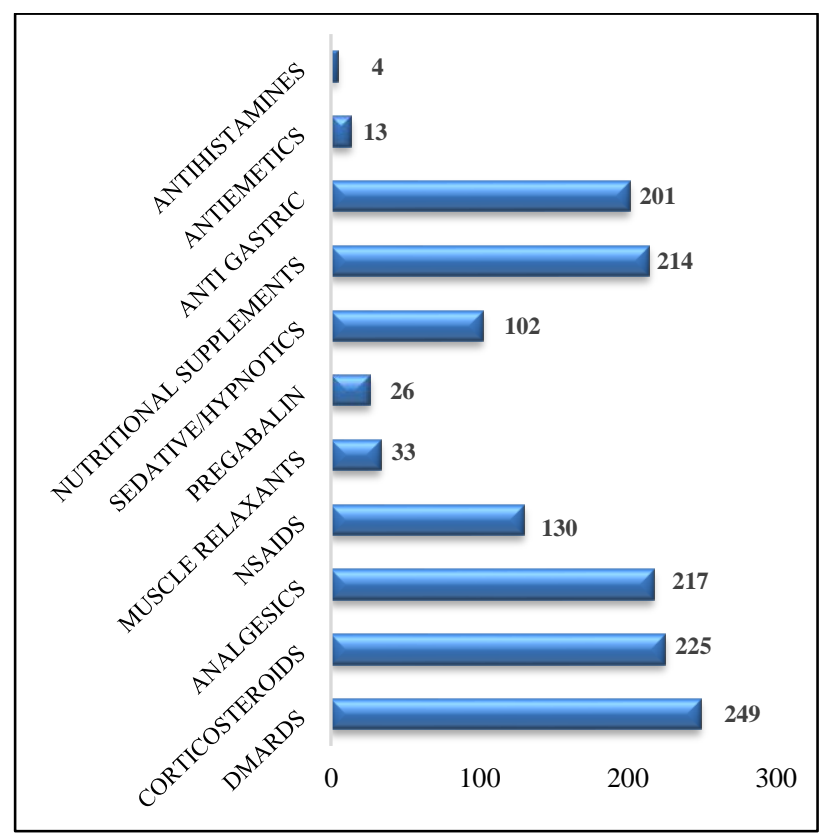

Figure 3: overall drugs prescribed in treatment of RA.

Table 2: Mean DMARD usage.

\begin{tabular}{|llll|}
\hline & Total & Mean & SE \\
\hline No of DMARDs & 264 & 1.21 & 0.06 \\
\hline Non-biological & 249 & 1.57 & 0.06 \\
\hline Biological & 15 & 1 & 0 \\
\hline
\end{tabular}

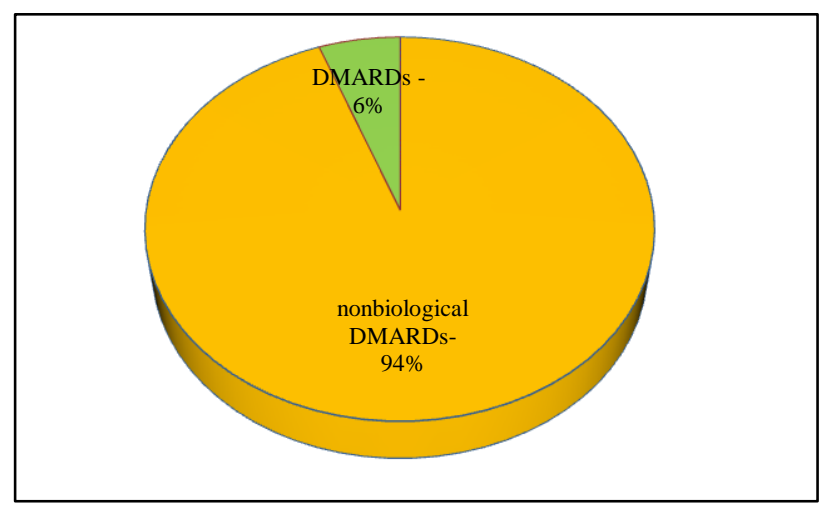

Figure 3a: Percentage of DMARDs used.

Table 3: Different doses of nonbiological dmards used in our study.

\begin{tabular}{|lll|}
\hline DMARDs & Dose $(\mathbf{m g})$ & ROA \\
\hline Methotrexate & $5,7.5,10,14$ & Oral \\
\hline Hydroxychloroquin & 200 & Oral \\
\hline Leflunamide & 20 & Oral \\
\hline Sulfasalazine & 500 & Oral \\
\hline
\end{tabular}


Among non-biological DMARDs, drugs used were methotrexate, hydroxychloroquine, leflunomide and sulfasalazine in different doses (Table 3). Hydroxychloroquine and methotrexate being the common ones (Figure 3c). Very few patients received biological DMARDs such as etanercept and infliximab (6\%) as they were prescribed rarely due to cost constraints.

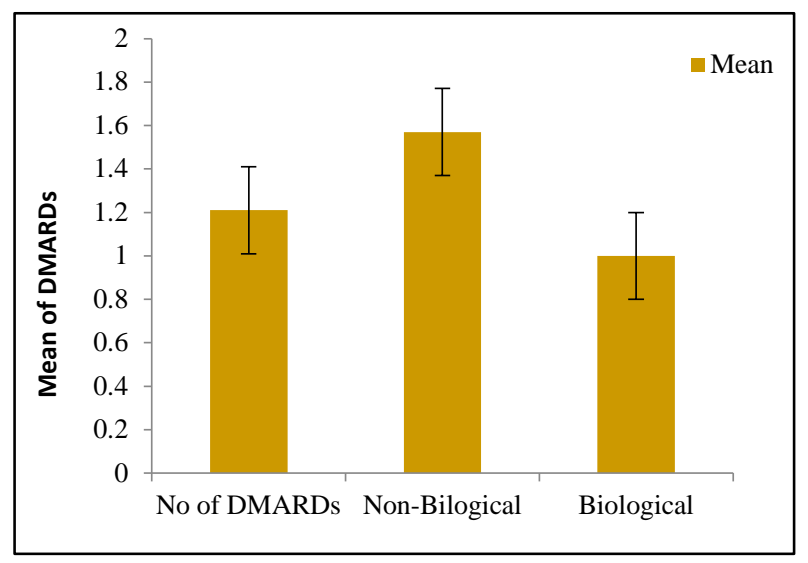

Figure 3b: Mean DMARDs used.

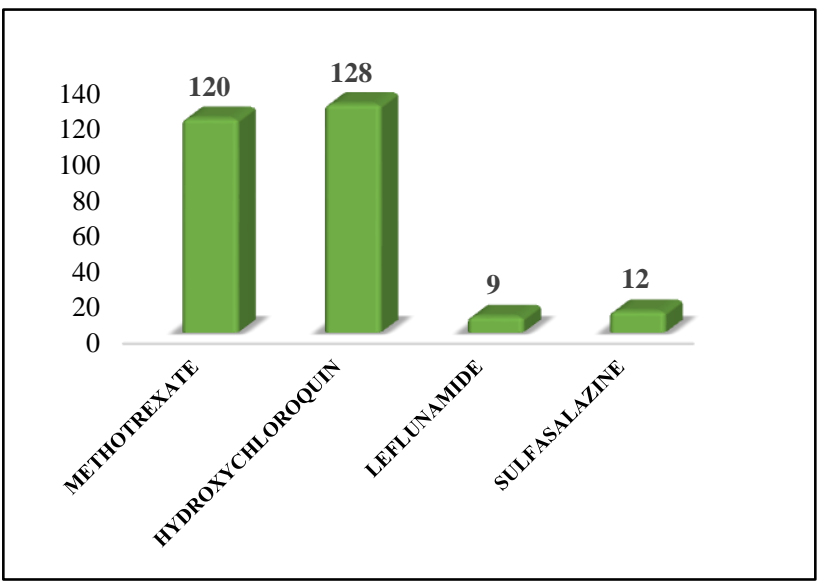

Figure 3c: Nonbiological DMARDS used in our patients.

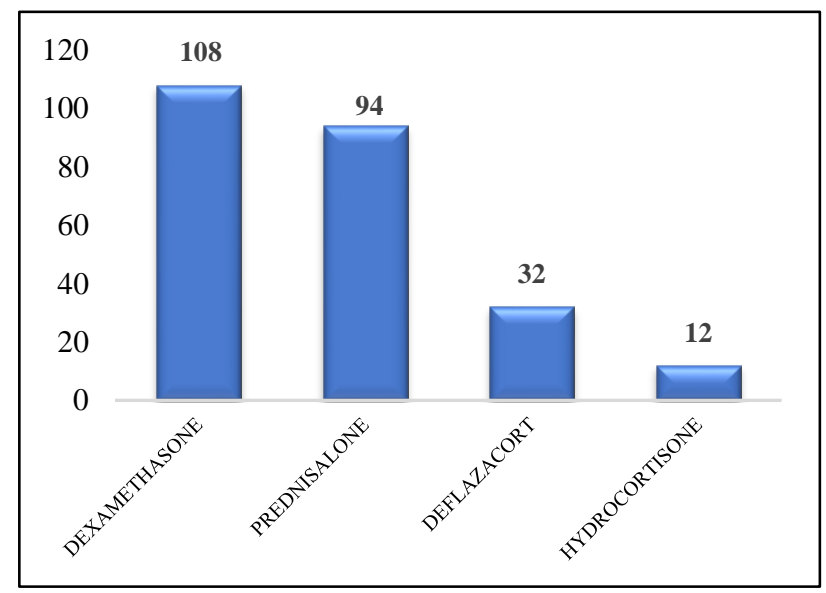

Figure 4a: Corticosteroid therapy.
Corticosteroid constitutes the other major group of drugs used in RA, with mean usage of steroids being $1.086 \pm 0.035$. Both oral and IV preparations were administered and drugs used under this category were dexamethasone, prednisolone, and deflazacort and hydrocortisone (Figure 4a, 4b).

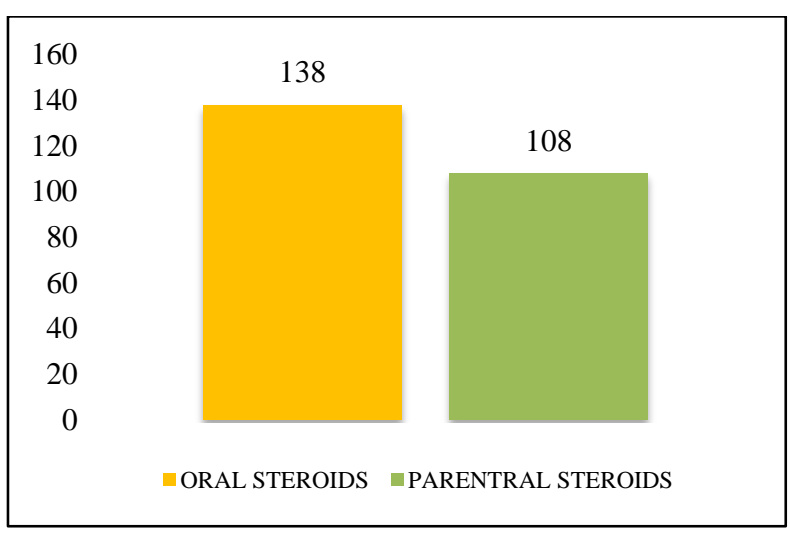

Figure 4b: ROA of steroids.

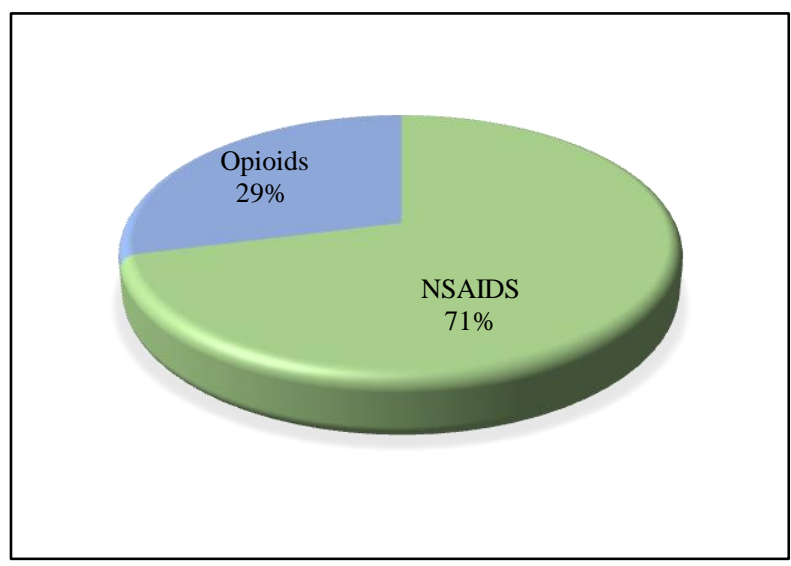

Figure 5a: Analgesic therapy.

Among the adjuvant group of drugs NSAIDs (130), opioids (53), Muscle relaxants (33), pregabalin (26), sedative/hypnotics (102) nutritional supplements (214), anti-gastric drugs (201), antiemetic's (13), antihistamines (4) were prescribed accordingly (Figure 6).

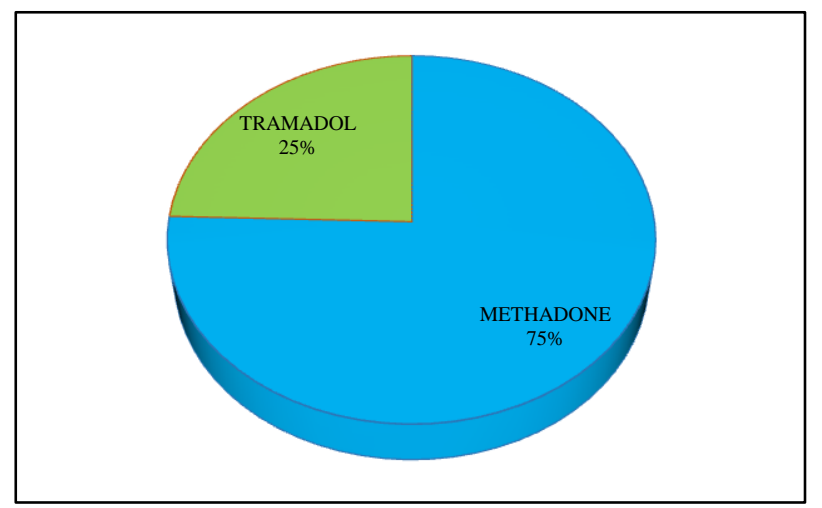

Figure 5b: Opiods used. 
The next major group of drugs were analgesics comprising of both NSAIDs and opioid analgesics (Figure 5a). Among opioid analgesics Methadone was used in $75 \%$ of patients and tramadol in rest $25 \%$ of patients (Figure 5b).

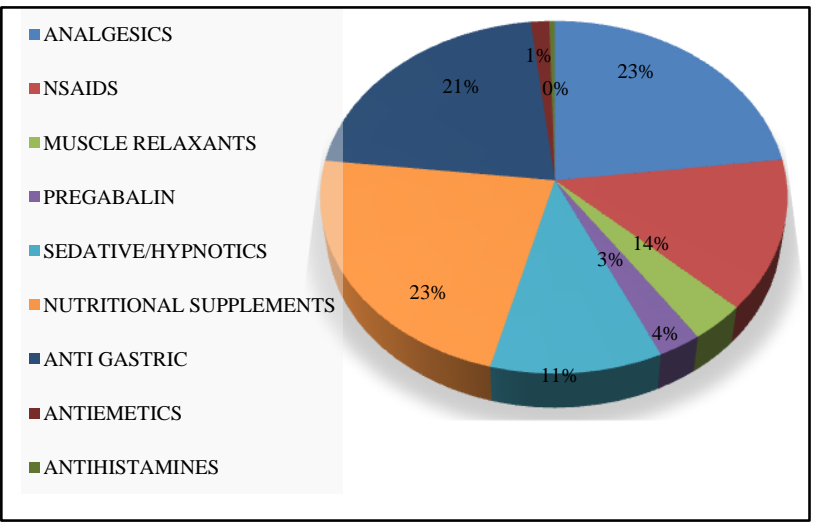

Figure 6: Adjuvant therapy.

Nutritional supplements constituted were oral preparations of iron, calcium, folic acid, cobalamine and multivitamin complexes.

Among 217 patients, 32 patients (13\%) suffered from other comorbid condition such as hypertension, diabetes mellitus and hypothyroidism (Figure 7).

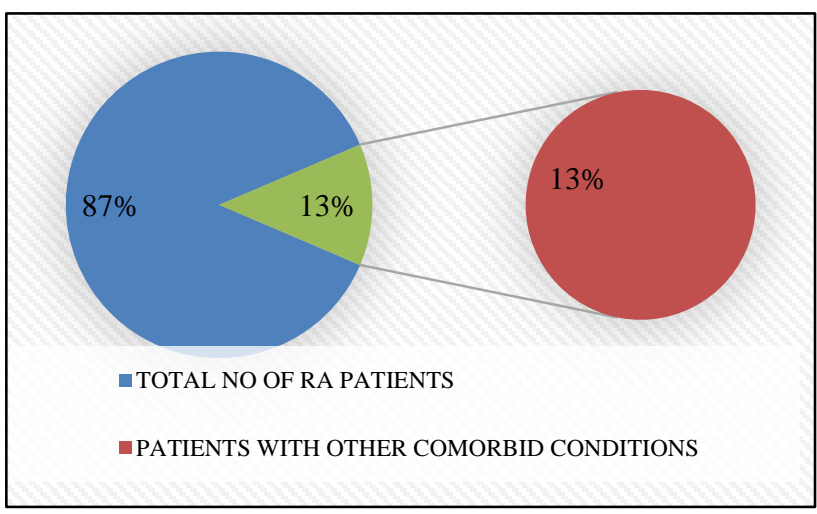

Figure 7: No. of patients associated with comorbid condition.

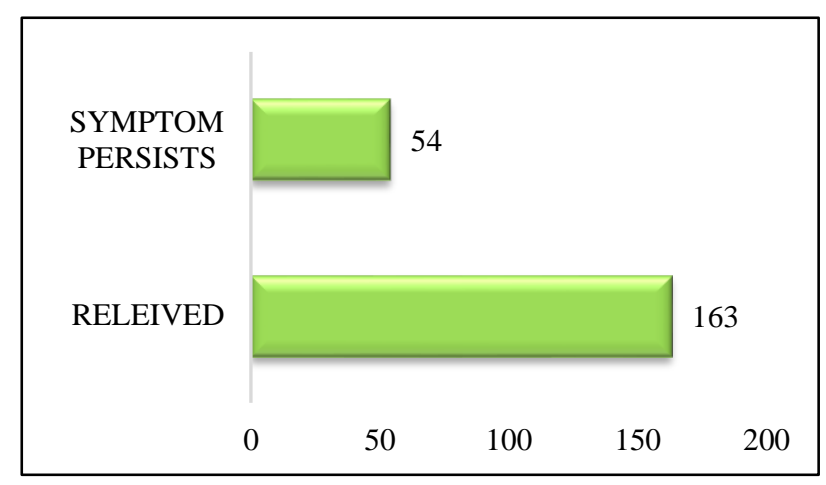

Figure 8: Treatment outcome.
Treatment outcome was assessed at the end of 15 months and 163 patients were relieved from symptoms and 54 patients continued to complain that the symptoms persisted after treatment course (Figure 8).

Table 3a: Association between treatment outcome and usage of glucocorticoids.

\begin{tabular}{|c|c|c|c|c|}
\hline \multirow{2}{*}{ Outcome } & \multicolumn{2}{|c|}{ Steroids } & \multirow{2}{*}{$\begin{array}{l}\text { Chi-square } \\
\text { value }\end{array}$} & \multirow{2}{*}{$\begin{array}{l}\mathbf{P} \\
\text { value }\end{array}$} \\
\hline & $\mathrm{Y}$ & $\mathrm{N}$ & & \\
\hline Relieve & 138 & 25 & \multirow[b]{2}{*}{$2.203^{\mathrm{a}}$} & \multirow[b]{2}{*}{$>0.05$} \\
\hline $\begin{array}{l}\text { Symptoms } \\
\text { persists }\end{array}$ & 50 & 4 & & \\
\hline
\end{tabular}

Table 3b: Association between treatment outcome and RA factor.

\begin{tabular}{|c|c|c|c|c|}
\hline \multirow{2}{*}{ Outcome } & \multicolumn{2}{|c|}{$\mathbf{R A}$} & \multirow{2}{*}{$\begin{array}{l}\text { Chi-square } \\
\text { value }\end{array}$} & \multirow{2}{*}{$\begin{array}{l}P \\
\text { value }\end{array}$} \\
\hline & $\mathrm{P}$ & $\mathrm{N}$ & & \\
\hline Relieve & 73 & 90 & \multirow[b]{2}{*}{$1.531^{\mathrm{a}}$} & \multirow[b]{2}{*}{$>0.05$} \\
\hline $\begin{array}{l}\text { Symptoms } \\
\text { persists }\end{array}$ & 19 & 35 & & \\
\hline
\end{tabular}

Table 3c: Association between treatment outcome and gender of patients.

\begin{tabular}{|c|c|c|c|c|}
\hline \multirow{2}{*}{ Outcome } & \multicolumn{2}{|c|}{ Sex } & \multirow{2}{*}{$\begin{array}{l}\text { Chi-square } \\
\text { value }\end{array}$} & \multirow{2}{*}{ P value } \\
\hline & M & $\mathrm{F}$ & & \\
\hline Relieve & 54 & 109 & \multirow[b]{2}{*}{$2.256^{\mathrm{a}}$} & \multirow[b]{2}{*}{$>0.05$} \\
\hline $\begin{array}{l}\text { Symptoms } \\
\text { persists }\end{array}$ & 24 & 30 & & \\
\hline
\end{tabular}

Table 3d: Association between treatment outcome and usage of DMARDs.

\begin{tabular}{|c|c|c|c|c|}
\hline \multirow{2}{*}{ Outcome } & \multicolumn{2}{|c|}{ DMARDs } & \multirow{2}{*}{$\begin{array}{l}\text { Chi-square } \\
\text { value }\end{array}$} & \multirow{2}{*}{ P value } \\
\hline & $\mathrm{Y}$ & $\mathrm{N}$ & & \\
\hline Relieve & 97 & 66 & \multirow[b]{2}{*}{$3.697^{\mathrm{a}}$} & \\
\hline $\begin{array}{l}\text { Symptoms } \\
\text { persists }\end{array}$ & 40 & 14 & & $<0.05$ \\
\hline
\end{tabular}

Table 4a: Association between duration of illness and usage of DMARDs.

\begin{tabular}{|c|c|c|c|c|}
\hline \multirow{2}{*}{$\begin{array}{l}\text { Duration } \\
\text { of illness }\end{array}$} & \multicolumn{2}{|c|}{ DMARDs } & \multirow{2}{*}{$\begin{array}{l}\text { Chi-square } \\
\text { value }\end{array}$} & \multirow{2}{*}{$\begin{array}{l}\mathbf{P} \\
\text { value }\end{array}$} \\
\hline & $\mathrm{Y}$ & $\mathrm{N}$ & & \\
\hline$<5 \mathrm{yrs}$ & 59 & 43 & \multirow{3}{*}{$6.572^{\mathrm{a}}$} & \multirow{3}{*}{$<0.05$} \\
\hline $5-10$ yrs & 54 & 18 & & \\
\hline$>10 \mathrm{yrs}$ & 24 & 19 & & \\
\hline
\end{tabular}

Table 4b: association between duration of illness and treatment outcome.

\begin{tabular}{|c|c|c|c|c|}
\hline \multirow{2}{*}{$\begin{array}{l}\text { Duration } \\
\text { of illness }\end{array}$} & \multicolumn{2}{|c|}{ Outcome } & \multirow{2}{*}{$\begin{array}{l}\text { Chi-square } \\
\text { value }\end{array}$} & \multirow{2}{*}{$\begin{array}{l}\text { P } \\
\text { value }\end{array}$} \\
\hline & $\mathrm{R}$ & $\mathrm{P}$ & & \\
\hline$<5$ yrs & 75 & 27 & \multirow{3}{*}{$0.261^{\mathrm{a}}$} & \multirow{3}{*}{$>0.05$} \\
\hline $5-10 \mathrm{yrs}$ & 55 & 17 & & \\
\hline$>10 \mathrm{yrs}$ & 33 & 10 & & \\
\hline
\end{tabular}


Table $3 \mathrm{a}$ to $3 \mathrm{~d}$ depicts the association between treatment outcome with, RA factor positivity DMARDs, corticosteroid usage and sex prevalence and Table 4a and $4 \mathrm{~b}$ shows association between duration of treatment with DMARDs used and treatment outcome. It was found that there is significant association between treatment outcome and duration of treatment with DMARDs.

\section{DISCUSSION}

This study dwells on the current trends in prescription patterns for treatment of RA and is undertaken over a period of 15 months (December 2013 to July 2015). Appropriate data gathered from a total 217 patients/prescription have been considered for medical audit.

\section{Epidemiological profile}

In this study, the incidence of RA has revealed a predilection for the age group of 45-50 years with mean age of $45.75 \pm 0.98$ (Table 1). In fact the occurrence of RA is higher in females (75\%) than in males $(25 \%)$ considered herein, which is noteworthy (Figure 2a, 2b). The incidence of RF positivity is very less i.e. 92 patients $(42 \%)$.

\section{Data pertaining to drug therapy}

The prescription patterns observed in this study conforn to the oral route of medication mainly and topical and parenteral routes less frequently. Majority of prescriptions noted herein highlights the oral use of medication with few exceptions.

Several treatment strategies have been suggested for drug therapy of RA. Accordingly polytherapy has been in vogue. Several classes of drugs have been used affording therapeutic benefit in RA with the particular drug being chosen, either singly or in approved combinations with or without adjuncts. Incidently, DMARDs, NSAIDs, opioid's (tramadol), antigastrics, corticosteroidsedative/hypnotics, muscle relaxants, antiemetics and nutritional supplements like, calcium, folic acid, iron, cobalamine etc (Figure 3).

DMARDs constituted the major group of drugs in treatment of RA, non-biological DMARDs were more commonly used compared to biological DMARDs as they were prescribed less frequently considering cost constraints with mean usage of DMARDs being $1.57 \pm 0.06$ and 1 respectively MTX and HCQ are more frequently prescribed (Table 2, Figure 3a, Figure 3b). Corticosteroid constitutes the other major group of drugs used in RA, with mean usage of steroids being $1.086 \pm 0.035$. Analgesics have been the mainstay and outnumber the other classes of drugs employed for polytherapy. Most of the patients were prescribed simple NSAIDs like combinations of diclofenac, paracetamol and coxibs unlike highly disabled ones who received opioid analgesics like tramadol $(25 \%)$ and methadone (75\%) (Figure 5b) combined with centrally acting skeletal muscle relaxants like chlorzoxazone. Rare/infrequent use of amitriptyline and alprazolam is also noted in order to sedate the patients suffering from insomnia due to high intensity pain due to disease process. Antigastric and anti-emetics add on to the list of drugs and contribute in gut protection. Corticosteroids are the next important group of drugs used in treatment of RA. Many studies have shown proven results in reducing the disease progression with early usage of steroids. Both oral and IV preparations were administered and drugs used under this category were dexamethasone, prednisolone, and deflazacort and hydrocortisone (Figure 4a, 4b). Among 217 patients, 32 patients (13\%) suffered from other comorbid condition such as hypertension, diabetes mellitus and hypothyroidism.

Treatment outcome was assessed at the end of 15 months and 163 patients were relieved from symptoms. The ACR/EULAR committee has proposed two definitions of remission in RA for clinical trials; a Boolean-based definition and an index-based definition. The Boolean based definition requires fulfilment of four criteria; TJC 41, SJC 41, CRP $41 \mathrm{mg} / \mathrm{dl}$ and PGA 41 (on a 0_10 scale) at any time point. The index-based definition is defined as a simplified disease activity index (SDAI) 43.3 at any time point. ${ }^{16}$ None of our patients who were assessed met standard ACR/EULAR criteria for remission of disease, but there was significant association between treatment outcome in terms of symptom relief and duration of treatment (Figure 8). It is worthwhile noting that for the purpose of description in this study, DMARDs, NSAIDs, steroids and analgesics have been regarded as the primary therapeutic agents whereas the others such as gastroprotectives, nutritional supplements, muscle relaxants, sedative/hypnotics have been considered as adjuvant/supplementary agents or secondary therapeutic agents. In a nutshell, a wide variety of therapeutic agents are in vogue for the drug therapy of RA.

\section{CONCLUSION}

The various treatment regimens prescribed enlighten the use of several heterogeneous drugs viz. DMARDs, NSAIDs, corticosteroids, opioids, gastroprotectives, sedatives, muscle relaxants and nutritional supplements. The treatment outcome and the duration of illness have significantly improved with rational use of DMARDs. Thus the study highlights and creates awareness on rational use of therapeutic agents available for treatment of RA and provides feedback to the prescriber. In conclusion, modest prescribing practices are evident in hospital where this study was undertaken and prescription patterns are in consensus with general trends in vogue, with a few changes, probably in the choice of established primary and adjuvant therapeutic agents. 
Funding: No funding sources

Conflict of interest: None declared

Ethical approval: The study was approved by the Institutional Ethics Committee

\section{REFERENCES}

1. Ramsay LE. Bridging the gap between clinical pharmacology and rational drug prescribing. $\mathrm{Br} \mathrm{J}$ Clin Pharmacol. 1993;35:575-6.

2. Pavani V, Manasa C, Nalini M, Krishna RT, Parmar YM. Study of prescribing pattern of common health problems. Intern J Pharm Bio Sci. 2012;2(4):22-31.

3. Crockett $\mathrm{AB}$. Use of prescription drugs: rising or declining? Nurs Clin North Am. 2005;40:33-49.

4. M de Vries TPG, Henning RH, Hogerzeil HV. Guide to good prescribing. A practical guide W.H.O. 1994.

5. WHO. The rational use of drugs. Report of a conference of experts, Nairobi, 25-29 November 1985. Geneva: World Health Organization; 1987.

6. WHO regional publications. Studies in drug utilization. European Series No. 8. Copenhagen: WHO regional publications; 1979.

7. Lipsky PE. Rheumatoid arthritis. In: Kasper Braunwald Fauci, Houser, Longo, Jameson, Editors. Harrison's principle of Internal Medicine 16th edition. New York: McGraw-Hill; 2005:1968-1976.

8. Shini VK, Aboobacker S, Pahuja S Pharmacoeconomic study of DMARDs in the management of rheumatoid arthritis. 2010;5(3);027.

9. Malaviya AN, Kapoor SK, Singh RR, Kumar A, Pande I. Prevalence of rheumatoid arthritis in the adult Indian population. Rheumatol Int. 1993;13:131-4.

10. Chopra A, Patil J, Billampelly V, Relwani J, Tandale HS. Prevalence of Rheumatic diseases in a rural population in Western India: A WHO-ILAR COPCORD Study. J Assoc Physicians India. 2001;49:240-6.

11. Van der Heijde D, Klareskog L, Rodriguez-valverde V, Codreanu C, Bolosiu H, Melo-Gomes J et al. Comparison of Etanercept and methotrexate, alone and combined, in the treatment of rheumatoid arthritis: two-year clinical and radiographic results from the TEMPO study, a double-blind, randomized trial. Arthritis and Rheumat. 2006;54(4):1063-74.

12. Goekoop-Ruiterman YPM, de Vries-Bouwstra JK, Allaart CF, van Zeben D, Kerstens PJSM, Hazes JMW et al. Clinical and radiographic outcomes of four different treatment strategies in patients with early rheumatoid arthritis (The best study). Arthritis and Rheumat. 2005;52:3381-90.

13. Grijalva CG, Chung CP, Stein CM, Mitchel EF, Griffin MR. Changing patterns of medication use in patients with rheumatoid arthritis in a Medicaid population. J Rheumatol. 2008; 47:1061-4.

14. Mishra R, Sharma BL, Gupta R, Pandya S, Agarwal $\mathrm{S}$. Indian rheumatology association consensus statements on the management of adults with Rheumatoid arthritis. Indian $\mathbf{J}$ Rheumatol. 2008;3(3):1-16.

15. Saag KG, Teng GG, Patkar NM, Anuntiyo J, Finney C, Curtis JR et al. American college of Rheumatology 2008 recommendations for the use of non-biologic and biologic disease-modifying antirheumatic drugs in rheumatoid arthritis. Arthritis Rheumat. 2008;59(6):762-84.

16. Felson DT, Smolen JS, Wells G. American College of rheumatology/European league against rheumatism provisional definition of remission in rheumatoid arthritis for clinical trials. Ann Rheum Dis. 2011;70:404-13.

Cite this article as: Ranganath DD, Ganguly D, Shankarappa M, Nagaraj KB, Chintha R. Analysis of drug prescribing trends in treatment of rheumatoid arthritis at a tertiary care hospital, Karnataka, India. Int J Basic Clin Pharmacol 2016:5:1790-7. 